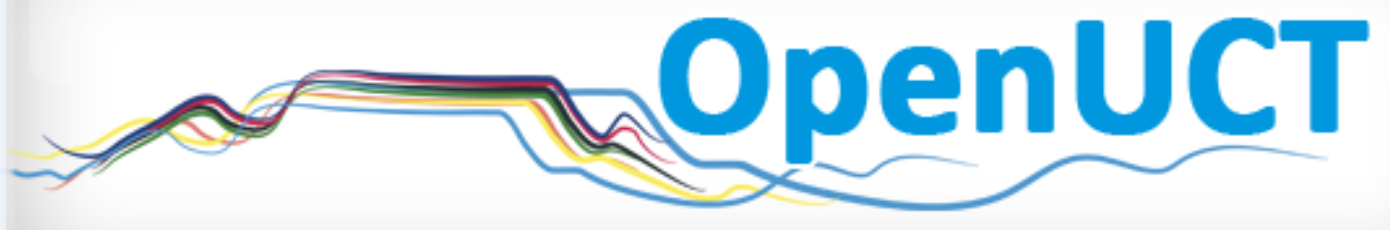

This is the post-print of Luckett, K. 2012. Working with 'necessary contradictions': a social realist meta-analysis of an academic development programme review. Higher Education Research \& Development. 31(3): 339-352. DOI: 10.1080/07294360.2011.631518.

It is made available according to the terms of agreement between the author and the journal, and in accordance with UCT's open access policy available:

http://www.openuct.uct.ac.za/sites/default/files/UCTOpenAccessPolicy.pdf, for the purposes of research, teaching and private study. 


\title{
Working with 'necessary contradictions': a social realist meta-analysis of an academic development programme review
}

\author{
Kathy Luckett \\ Department of Sociology, University of Cape Town, Cape Town, South Africa

\begin{abstract}
This article addresses the problem of making programme evaluation sufficiently meaningful and cognisant of context such that practitioners, in this case of academic development, can gain new understandings of their situation in order to improve their practice. In order to do this, the paper uses Archer's morphogenetic framework to deepen the methodology of academic review on an academic development programme. The theory enables a richer understanding of how the programme developed within particular national and institutional situational logics and of the relationships between structure, culture and agency.
\end{abstract}

Keywords: academic development; programme evaluation; social realism; sociology of higher education; South African higher education

\section{Introduction}

No project, however well intentioned, can simply claim the moral high ground ... in the (re)making of higher education, critique is an indispensable resource. (Clegg, 2009, p. 412)

This article sets out to explicitly apply theory to empirical, context specific, higher education research - in this case evaluation research. It also responds to Clegg's (2009) urging to articulate the situational logics and contextual constraints on Academic Development practice. Academic development generally relates to staff, curriculum and student development practices aimed at improving the quality of teaching and learning in higher education. Until recently, the focus of academic development in South Africa has been on student development.

The article emerges from my own frustration with the recipe-like methodologies used in academic review and programme evaluation in higher education. Elsewhere (Luckett, 2010) I have critiqued the 'common sense' pragmatic approach to quality assurance in higher education for its decontextualised, reified versions of 'good practice' and for the way in which it assumes that descriptive, empirical-level 'evidence' (based on statistics and/or people's experiences) provides adequate grounds for making judgements about quality - without recognising that these are the (indirect) effects of structural and cultural causal mechanisms that create the conditions for human agency. The approach to programme evaluation advocated in this paper draws on 'realist evaluation' (Pawson \& Tilley, 1997) and falls within the 


\section{K. Luckett}

'improvement-orientated' model of evaluation (Rossi, Lipsey, \& Freeman, 2004) but is relatively unknown in the quality assurance of higher education literature (Luckett, 2010).

In 2009, I was asked to coordinate an internal review of a large academic development programme at a research-intensive South African university in preparation for a pending external review. The Academic Development Programme (ADP) concerned is one of the oldest and most established in South Africa, with a richly documented history going back for 30 years. Currently the programme comprises a central coordinating management structure and three central units: language, numeracy and testing, and faculty-based units. In order to highlight the interaction between the agency of academic development (AD) practitioners and institutional structures and cultures, I decided to focus particularly on the internal reviews of the four most established faculty-based units - those in Science, Commerce, Engineering and the Health Sciences.

The coordination of the internal review of the ADP provided an opportunity to explicitly utilise social theory to deepen the methodology and subsequent analysis of an academic review. I employed Archer's (1995, 1996, 2000) social realist morphogenetic framework to inform my design of the review methodology and subsequently for structuring the metaanalysis, with a view to achieving greater depth and rigour in the analysis. The theory provided a framework for relating empirical level data (from the unit self-review portfolios) and events (such as the review workshops) to underlying socio-economic and organisational power structures and institutional cultural systems. I wanted to understand the ways in which, in this particular context, structural and cultural 'emergent powers' (Archer, 1995) have non-deterministically conditioned (enabled or constrained) human agency and intentionality. Archer (1995) insists that, although human actors find themselves involuntarily inserted into prior differentiated distributions of power and resources, creating 'situational logics' that predispose them to act in certain ways, structural conditioning is always mediated by human reflexivity - such that some actors can and do choose to act counter to their own vested interests.

The article provides a brief introduction to Archer's key concepts, describes the method used to gather and analyse the data and then uses Archer's morphogenetic cycle as a framework for analysing the data.

\section{Theoretical framework}

Due to space limitations, a condensed summary of Archer's $(1995,1996,200)$ social realist theory of social change is provided here. Archer (1995) aims to offer a practical social theory that can account for patterns of social phenomena, providing an explanatory methodology that takes history and context seriously. Following Bhaskar's (1979) critical realism, Archer views society as open, stratified and differentiated - distinguishing between three levels: the empirical (transitive, mediated and experienced and/or observed by our senses, e.g. interview data), the actual (transitive events that are an effect of social interaction and causal mechanisms, e.g. historical accounts) and the real (intransitive structures, e.g. class structures, that are relatively enduring, with potential powers and properties that are activated as causal mechanisms only when mediated or triggered by human agency). She understands structure, culture and agency to be analytically distinct strata of reality. Structures are viewed as relatively enduring, anterior, social objects that possess causal powers and are neither observable nor reducible to social interaction. Archer (1995) distinguishes between structural emergent properties (SEPs) that include systems, institutions and roles with primary dependence on necessary material resources 
and their distributions and cultural emergent properties (CEPs) that include the (again differentially distributed) stock of existing ideas, beliefs and ideologies (contained in particular discourses). Cultural emergent properties operate similarly to SEPs except that they exhibit necessary logical relations as opposed to necessary material relations. Archer uses the concepts of SEPs and CEPs to describe what she terms 'situational logics' - configurations of SEPs and CEPs brought together by particular institutions. These situational logics set up differential power relations and shape the practical situations, daily experiences and events that individuals encounter. Some situational logics exhibit 'high systems integration' based on 'complementarities' (wherein the SEPs and CEPs are mostly compatible and complementary, creating the potential for social reproduction), whilst others exhibit 'low systems integration' based on 'contradictions' (wherein the SEPs and CEPs are predominantly incompatible and contradictory, creating tension and the potential for systemic transformation). A further key distinction in these variations of situational logic is whether these relations are necessary (internally related and logically inevitable) or simply contingent (a function of the context). She also distinguishes between system level (a function of SEPs and CEPs) and social level (the social or socio-cultural interaction of human actors). Table 1 summarises the various typologies that Archer's theory creates. This Table will be used in the analysis that follows to characterise the situational logics implicated in the development of an Academic Development programme. In Archer's (1995) morphogenetic cycle an understanding of chronological development is important: SEPs and CEPs exist at Time1 (thus providing structural and cultural conditioning), prior to social and sociocultural interaction, shaping the situations people involuntarily find themselves in and predisposing them (non-deterministically) to take up certain courses of action. This objective structural conditioning (SEPs) predisposes agents to act in certain ways and provides normative reasons to justify their actions, selected from the given stock of ideas and discourses (CEPs). However, Archer notes that 'the constraints and enablements of a situation are not the same as our powers of description or conceptualisation' (Archer, 1995, p. 196), because these exist objectively and independently of actors' knowledge of them. Thus structural and cultural conditioning is already set up (Time1) before human actors with particular intentions, concerns and projects located in particular roles and positions in institutions begin interacting with each other at Time2 - Time3 (social and socio-cultural interaction). It is here, at the second stage of the morphogenetic cycle that human agency, in the form of personal emergent properties (PEPs) is exercised.

Table 1. Summary of cultural and structural morphogenesis/morphostasis at system and social levels (adapted from Archer, 1995, p. 303).

\begin{tabular}{lllllll}
\hline & \multicolumn{2}{c}{ Contradictions } & & \multicolumn{2}{c}{ Complementarities } \\
\cline { 2 - 3 } & Necessary & Contingent & & Necessary & Contingent \\
\hline Situational logic & Correction & & Elimination & & Protection & Opportunism \\
CEPS: Cultural system & Syncretism & & Pluralism & & Systematisation & Specialisation \\
Socio-cultural interaction & Unification & & Cleavage & & Reproduction & Sectionalism \\
SEPs: Structural system & Compromise & Competition & & Integration & Differentiation \\
Social interaction & Containment & Polarisation & & Solidarity & Diversification
\end{tabular}


Table 2. Morphogenetic cycle for the ADP review.

\begin{tabular}{ll}
\hline Periodisation & \multicolumn{1}{c}{ Morphogenesis/morphostasis } \\
\hline Time1 (up until early 1990s) & Structural/cultural conditioning \\
Historical background & \\
Time2 - Time3(mid-1990s- 2009) & Social/socio-cultural interaction \\
Period under review & Structural/cultural/agential elaboration? \\
Time4 (2010 -) & \\
Improvement plans and forward & \\
\hline
\end{tabular}

Some institutional roles are necessarily related to each other (for example teachers and students require each other in order to exist), whilst others are contingent to the context. Exactly what emerges from a particular period of social/socio-cultural interaction (Time2-Time3) is contingent on the context of situation and cannot be predicted. Analytic histories of particular contexts are required to explain the outcomes of social interaction, which may involve structural and cultural change or reproduction at Time4. The three stages of the morphogenetic cycle are used in this meta-analysis to periodise the review as follows.

The indeterminacy of morphogenesis is partly a consequence of what kinds of agency particular groups of people are able to exercise (primary agency, corporate agency or as individual social actors in particular roles). At Time1, 'primary agents' are collectivities of people who share the same life chances - they are simply shaped by the SEPs and CEPs of their natal contexts, which are not of their own making and exercise no agential power in society, except as an unarticulated aggregated effect, that is, they exercise 'demographic power' simply by virtue of their numbers. In the institution under analysis black students are typically portrayed as exercising only primary agency, that is, they influence the situation only through the impact of their (increasing) numbers and high failure rates. In contrast, at Time1 some people have become 'corporate agents', that is, self-conscious interest groups who organise themselves to undertake collective action in order to achieve a particular articulated demand or ideal. In the review under analysis, AD practitioners are an example of corporate agents (Clegg, 2009) who have an articulated goal for change and work collectively towards achieving it in a particular institutional context. Time2-Time3 represents the social interaction between primary agents and corporate agents. In the process, Archer's third category of human agency emerges - individual social actors who fill particular social roles, dialectically changing their personal identities and the social role as they do so. Thus, in the process of social and cultural interaction and change the human agents involved develop their PEPs - such that both agency and structure are transformed, that is, double morphogenesis can occur. However, Archer (1995) warns that this is unlikely to be what anybody intended - 'socio-cultural complexity is an unintended consequence of interaction' (p. 251). Archer's definitions of different types of agency are also employed in the analysis that follows.

\section{Methods}

The process for the internal review was initiated by a workshop where the template to be used for writing individual unit self-review portfolios was discussed. Thereafter, each Head of Unit wrote a review report following the template and in consultation 
with their units. Each report was presented at a unit-specific workshop where AD practitioners concerned, academic staff and the relevant Deputy Dean were invited to discuss the report. Summary notes of the proceedings of these workshops provided some of the most interesting data-sources for this paper. Thereafter, each unit developed an improvement plan and a high level summary self-review portfolio for the whole programme was written up. For the purposes of this paper, I conducted an interview with the Director of the ADP to check and correct my preliminary analysis of the data.

Given the large amount of data available, I adopted a fairly deductive, theory-driven method of data-selection. Having used Archer's concepts initially to frame the template for the production of the self-review portfolios, I used her morphogenetic cycle to periodise the data. Thereafter, I used her concepts of SEPs, CEPs and PEPs to analyse the relations between national and institutional structures and between institutional structures and AD corporate agency. This enabled me to map the historical development of the ADP in terms of the shifting institutional 'situational logics' in which $\mathrm{AD}$ practitioners have been, and still are, bound to act. The paper thus focuses on an analysis of the structural and cultural systems that have conditioned this programme.

\section{Data analysis}

\section{Time1 (1980s-early 1990s) structural/cultural conditioning}

Situational logic

When the Academic Support Programme (ASP) was established at the university in 1980 , it entered a situational logic of 'necessary complementarities', where a conjunction of both structural and cultural morphostasis would, according to Archer (1995), suggest a logic of protection and possible stagnation. Nationally, under apartheid, higher education provision had been allocated by race group and the university concerned enjoyed an excellent reputation with few exogenous pressures to change. The fact that it was an elite, predominantly white male institution that had reproduced itself historically went largely unquestioned. Its culture was liberal-humanist and collegial, underpinned by strong disciplinary cultural and structural systems.

However, in keeping with its liberal-humanist culture, there had been a vocal but minority anti-apartheid tradition throughout the 1960s and 1970s that became more strident in the 1980s. Senior leadership now stretched the limits of apartheid legislation to admit small numbers of black students. It soon became evident that these students needed extra support, hence the origin of the ASP. Early on a tension developed between the desire to admit black students and what this would mean for 'standards', that is, the traditional curriculum and its mode of delivery, which was taken as given (Scott, Yeld, McMillan, \& Hall, 2005). As the anti-apartheid struggle gathered momentum and gained support in some sectors of white civil society, a (weak) disjunction developed between the liberal-humanist cultural system of the university, which supported the struggle for democracy (cultural morphogenesis), and its structural system, which remained intact (structural morphostasis). This allowed the ASP to ride on the high moral ground of the 'struggle', although structurally it remained weak and marginalised. The disjuncture between anti-apartheid ideas and the inherited traditional structure during this period suggests the beginnings of a situational logic of 'contingent contradiction'. 


\section{K. Luckett}

However, because the contradictions remained contingent rather than necessary, there was always the possibility of elimination if the ASP became too threatening to the traditional standards of the university. This led to a situational logic of polarisation between the advocates of academic development and those determined to maintain the traditional standards of an elite institution.

\section{$A D$ practice}

Early AD practice at the university involved a focus on student development through the offering of 'add-on' foundation courses and tutorial programmes. These were viewed as remedial and preparatory and therefore not credit-worthy or subsidy earning, thus the ASP remained dependent on soft funding. During this period the ASP was confined to the micro practices of teaching and learning with minimal impact on the mainstream curriculum. As a result there was a high failure rate of black students in their second year when they moved from the supported environment of the ASP courses to unsupported mainstream courses. By the mid-1980s it was clear that supplementary tutorials were inadequate to overcome the severe educational backlogs of black students and the emphasis shifted to offering foundation courses in key disciplines (Scott, Yeld, McMillan, \& Hall, 2005). The late-1980s also saw the beginnings of test development for an alternative admissions policy in an attempt to capture for admission those black students with the 'potential to succeed'.

In 1993 the ASP was renamed the Academic Development Programme (ADP), indicating the desire to shift to more systemic solutions. Most significantly this involved establishing Extended Curriculum/Degree Programmes, where previously add-on foundation courses were integrated into the bottom end of mainstream curricula. However, throughout this period, although society exerted exogenous pressure on the university, structurally the AD project remained powerless and therefore marginal. Organisationally it exercised little political power or influence on academic departments. It remained largely dependent on soft funding and its educational expertise was not recognised by the institution. However, as long as the problem of 'black students' was dealt with by AD practitioners and did not impinge on 'business as usual', the institution was prepared to tolerate it. In practice, the idea of equity was reduced to a focus on micro pedagogic practices (Clegg, 2009). In recognising their own institutional impotence, ADP leadership hoped that politicised black students would develop a corporate agency that might change the university:

\footnotetext{
The university was big, powerful and conservative. A few ADP lecturers were the change agents - but it was politically and culturally impossible to say that we would change the institution, this was not feasible. We had no chance of being recognised. Our only choice was to work in the spaces available or not at all. In fact, the black students were our only real hope of change agents. (Interview, ADP Director, 24 June 2010)
}

Thus, although committed to equity and social justice in terms of values, the ADP's moral and political project that sided with black students against the white university was severely constrained during this period both by the enduring colonial and disciplinary structures of the university and by the structural and cultural 'disadvantage' of the black students they championed. This, in turn, constrained the possibility of black students' academic success. These tensions were captured in the following interview:

Right from the start AD had an equity agendaønot only equity of access, but of outcomes as well. But you can't read off from what was done [practice] to our thinking about what 
ought to be done [discourse]. . . . There was a huge tension between what was possible and our ideas. ... We believed that increasing the number of capable and coping black students on campus would in itself create a demand for change. Our AD effort in the ' 80 s was to reduce the whiteness of the university by ensuring increasing numbers of places for black students and - critically - that they would cope academically. (Interview, ADP Director, 24 June 2010)

\section{Time 2-Time 3 (mid-1990s-2009) social/socio-cultural interaction}

\section{Situational logic}

During the period under review, the ADP continued to work within a situational logic of sharpening contradictions that started shifting from contingent to necessary contradictions. The contradictions in the social system between equity and redress versus excellence/quality/development were exacerbated by the structural effects of the political transition of 1994 and mirrored in the university. Internally, this contradiction manifested itself as a tension between teaching and research. 1 In Archer's (1995) terms, the political transition led to structural morphogenesis, but the analysis shows that although incomplete, structural changes were resisted from within the institution by a return to cultural morphostasis - thus creating a disjunction between the structural and cultural systems, leading to a situational logic characterised by containment.

Post the transition to democracy, the African National Congress government's early embrace of a neo-liberal macro-economic policy meant that the promise of funding for equity and redress mechanisms in higher education made in early policy documents was not kept. Instead, a small black elite (who could pay for good higher education) began to emerge, based on access to state power and the Africanisation of the civil service. Compulsory affirmative action (read Africanisation) that was imposed on the private sector through the Employment Equity Act of 1998, plus an exodus of white professionals, created a 'scarce skills' crisis, which in turn put pressure on the professional faculties of the university to produce large numbers of black graduates, precisely in those areas where historically there were very high failure rates.

On the higher education policy front, a key document, the White Paper for the Transformation of Higher Education (Department of Education, 1997) itself battled to hold together the contradictory discourses of equity and redress and of economic development in a global market. Regarding AD, it supported the development of Extended Degree Programmes and promised funding for AD work. Another seven years went by before this promise was implemented. Despite cuts in state spending, there was a raft of HE policy development during this period of 'strong steering' by the state (Badat, 2009) leading to greater state intervention than ever before, particularly in the areas of planning, funding and quality assurance. Through these steering mechanisms, the state attempted to impose its 'transformation agenda' as a moral imperative on all HEls but without increasing the HE budget. The National Plan for Higher Education of 2001 stressed the importance of improving the efficiency of the HE system and warned that institutional interests would not be allowed to stand in the way of transformation. In 2003 the New Funding Framework finally formalised the allocation of limited funding for AD programmes (Foundation Grants).2 This signalled an important structural shift, it was the first time that stable dedicated funding became available for AD in South Africa. This comment captures well the disappointment in the descent from the rhetoric of policy to the ambivalences and compromises of implementation as experienced by $A D$ : 


\title{
K. Luckett
}

We should not assume that political pressure has been translated into funded policy mechanisms for higher education. In fact the mechanisms have been quite weak and a lot of the pressure has had negative unintended consequences. ... In some ways the state has been ambivalent in its push for equity, for fear of destabilisation. The main pressure for change has been that society is changing. In order to make it financially, HEls have had to enrol black students - but half of them don't make it. (Interview, ADP Director, 24 June 2010)

During this period, within the institution, an attempt by senior management to follow national policy on outcomes-based education and the development of a national qualifications framework by imposing programmes on traditional disciplinary curriculum structures was opposed by many academics in the Humanities and Sciences. In reaction to this and other state interventions, the university tried to protect its traditional identity and culture by consolidating the disciplines and by re-inventing itself as a 'research-led', 'world-class' university (suggesting perhaps a return to cultural morphostasis). In what appears to be an attempt to portray an ivy-league identity, strategic documents of the time describe the university as a world-class, research-intensive, medium-sized contact university that offers a good student learning experience (for very high fees). There was a 'necessary complementarity' between this intensification of a research culture and the development of improved organisational structures and resources for research and the old elitist aspirations and ethos. But in keeping with the advent of managerialism at the top, greater accountability for research outputs was built into the performance management instrument for academics. However, the cultural system continued to construct academics as collegial and autonomous researchers and traditional departmental and disciplinary structures continued to form the basis of the structural system.

At the same time the institution was obliged to admit greater numbers of black students, who, with some celebrated exceptions, continued to fail in large numbers, despite $A D$ interventions. 3 In a context of relatively limited resources, this served to exacerbate the contradictions between excellence and equity and between research and teaching, leading to the side-lining of AD work by most academics. These tensions were expressed by mainstream academics at the review workshops:

\footnotetext{
Most of us are frustrated as teachers because the time that we spend on teaching eats into our research time. (Workshop notes, 19 November 2009)

If $50 \%$ of black students don't make it anyway, surely we can get rid of them sooner? (Workshop notes, 19 November 2009)

When I first lectured in mainstream, I put such passion into my teaching, but the rate-forjob [the performance management system] does not reward this. The university gives no incentive for this work. (Workshop notes, 24 September 2010)
}

And by AD leadership:

\begin{abstract}
AD was a containable endeavour. The university could become more research-led and at the same time allow AD to grow. There was divergence and this let the AD people get marginalised. (Interview, ADP Director, 24 June 2010)
\end{abstract}

The heightening of these internal contradictions, such that the equity agenda and AD work were structurally and culturally contained, was alluded to in the report on the institution's audit. The report noted a misalignment between the commitment to transformation by senior management and ${ }^{8}$ the lack of implementation in everyday practices: 'the institution has no way of enforcing its student equity policy' (Higher 
Education Quality Committee [HEQC], 2007, p. 49). The Higher Education Quality Committee also pointed out that governance of teaching and learning was weak Resulting in lack of institutionalisation of good teaching practice. It questioned why the ADP remains poorly integrated in the Faculties and recommended that the institution review this relationship and make better use of the former's educational expertise (HEQC, 2007).

\section{AD practice}

In keeping with the situational logic of polarisation and containment during this period, in 2000 the ADP was located in a newly established faculty, the Centre for Higher Education Development (CHED). The faculty has primarily a developmental as opposed To a teaching and research function and is based on top-sliced and soft funding. This Has had the effect of both giving AD work greater status and coherence, but also of ghettoising AD programmes and practitioners in the faculties. This was confirmed by some mainstream academics at the review workshops:

We haven't given AD staff a real home in the [mainstream] Faculty, they don't live in Departments. (Workshop notes, 26 October 2009)

We should include recognition and support for education research in our strategic plans so that AD practitioners feel more part of their department. (Workshop notes, 19 November 2009)

AD staff is not involved in mainstream [teaching], this is unhelpful, they should teach higher up in the curriculum.... We don't benefit from our connection with CHED and ADP on pedagogy. . . . Perceptions need to be changed. (Workshop notes, 19 November 2009)

At the same time, boosted by state funding (structural morphogenesis), the ADP has developed a stronger presence in most faculties, with some AD practitioners located in departments and Extended Degree Programmes being rolled out in all faculties. In some cases, AD work is beginning to be more integrated into mainstream faculty work. For example, in response to a national health policy move to a primary health care approach, $\mathrm{AD}$ practitioners in the Faculty of Health Sciences became centrally involved in developing a new Bachelor of Medicine, Bachelor of Surgery/Chirurgery curriculum. In a move that heralded later developments, they refrained from focusing on micro-teaching and instead worked on curriculum development, staff development, the use of educational technology and educational research. More recently, in the Faculty of Commerce, AD practitioners have been authorised to integrate the principles of good teaching practice developed in $A D$ across the faculty.

Also, during this period, AD practice has been able to realise a more holistic understanding of student learning. There has been a new emphasis on meeting black students' psycho-social needs and attempting to alleviate the alienation that they experience because of stigmatisation and the 'whiteness' of institutional culture. These new practices have been underpinned by identity and voice discourses such as the new literacies approach and socio-cultural, constructivist and situated theories of learning. Thus new cultural reasons have been articulated for why black students continue to fail.

However, a problem for AD practitioners is that their development work continues to be given little recognition and reward by the 'research-led' university. Some complained in the review workshops that they have insufficient time to carry out research, that 
educational and development work is not recognised for promotion purposes and that the university does not offer a proper career track for AD practitioners.

During this period, the internal contradiction between research and teaching has also impacted on the identities and agency (PEPs) of AD practitioners. Many have bought into the university's research culture and become 'research active', but they tend to be located in the centre rather than in the faculties, where teaching and development workloads tend to be heavier. This period has also seen the emergence of Higher Education Studies as a field and the beginnings of formal staff development, albeit on a voluntary basis.

\section{Time4 (2010-) structural, cultural and agential elaboration \\ Situational logic}

At the time of the AD review, there is an increasing sense that the contradictions between equity and excellence and between teaching and research in this university have reached the point where, in Archer's terms, they would be termed necessary contradictions, that is, the situational logic now requires them to co-exist. The institution may be moving towards a conjunction where there is evidence of both structural and cultural systems morphogenesis, possibly leading to structural and cultural elaboration (transformation). If this is the case, then the situational logic becomes one of correction, that is, both sides will have to adapt, leading to structural and cultural compromise with unintended consequences!

The university has new senior leadership and a new Strategic Plan, which reflects the institution's continued self-satisfaction: 'both research and teaching and learning are being conducted very successfully and at a very high level' (University of Cape Town [UCT], 2009, p. 1). The new Plan sets out the vision of an Afropolitan university and continues to affirm world-class aspirations: the university is to be 'a brilliant example of a developing-world university' and research and teaching are to 'give space to African voices' (p. 11). Research is still given a privileged position, it should be excellent and 'researchers need time, money and good conditions to be successful' (p. 11). The full contradictions become evident where, on transformation, the Plan expresses the desire that the full diversity of South Africa be represented and that the university be experienced by all as 'inclusive and nurturing' (p. 5). In the same breath it notes the 'significant challenge to address the continued discrepancy in performance between black and white students' (p. 6). In this regard, staff development is mentioned to enable staff to 'cater effectively for student diversity in mainstream courses' (p. 13). A four-year degree structure is mentioned tentatively but there is uncertainty about where the additional resources and teaching expertise for this will come from. These rhetorical statements sound a little hollow when compared with the realism expressed by a Deputy Dean at one of the review workshops with regard to curriculum development:

We can't do this across the faculty because our staff isn't interested. . . . We could get buyin if student numbers were smaller and if they had a greater chance of success. If we marked scripts and saw good results we would be energised, then perhaps people would have the energy to put AD into the mainstream. (Workshop notes, 19 November 2009)

\section{$A D$ practice}

In the current conjuncture, AD work involves a much greater engagement with mainstream curricula and staff and a growing focus on policy and strategy work, especially 
as related to curriculum development and retention strategies. This was noted by the Heads of two of the leading AD units:

\begin{abstract}
We now work across the degree and look at academic and affective factors ... AD has moved from being a back-door job to being central in the faculty - because we have shown results. People want to pull AD into the mainstream. ... Professional pressure has also helped, this supports working to improve the equity through-put profile. (Workshop notes, 19 November 2009)
\end{abstract}

We now avoid doing intensive teaching ourselves. Rather the disciplines have to be relevant to the production of professionals. So our focus is on curriculum rather than student development. (Workshops notes, 19 November 2009)

What this high-level meta-analysis subsumes is the differences in situational logics between the different faculties. For example, the professional faculties have 'projected identities' that are more strongly driven by exogenous pressures, whilst the humanities and sciences have 'introjected identities' and are more strongly driven by the endogenous interests and cultures of the disciplines.

The AD Director argues that despite these shifts in AD discourse towards institutional change management, the mission, goals and values of $A D$ have remained constant:

\begin{abstract}
Equity in terms of access and outcomes remains our central mission. What has changed is the coming together of the equity and development agendas. The only way South Africa can produce adequate graduate output is to deal with the success rate of black students.

(Interview, ADP Director, 24 June 2010)
\end{abstract}

\title{
Domain assumptions in $A D$ discourse
}

Archer's $(1995,1996)$ social theory prioritises practice over discourse, but accepts that they work dialectically and non-deterministically shaped by prior social and cultural conditioning embedded in the situational logic of a particular time and place. I now turn to a brief critical analysis of the 'common sense' AD discourse in this institution that was evident during my research.

Archer (1995) notes that in the process of social and socio-cultural interaction, the PEPs of the human agents involved also change; double morphogenesis occurs. One can detect this in the case of the AD practitioners in this study: social agents who began their careers as teachers and educational experts have been pushed by the contradictions of the situational logic to become researchers of education, as this is the only way they can gain credibility (and promotion) in the institution (a logic of correction). (There is still a debate in $A D$ as to whether or not this contributes to development work, which remains under-recognised.) This agential morphogenesis also involves a shift in personal identity, often from that of heroic activist or saviour and 'mother' of students to that of scholar and/or change manager. This may involve a difficult ontological shift from being against the status quo to being for it.

Early AD discourse constructed black students as victims - of apartheid and of disadvantaged' state schooling. This was a consequence of its origins as a political and moral project linked to the anti-apartheid struggle and the right of access of oppressed black students. This led to an early polarisation in the discourse: AD was for black students and against a politically conservative white university. But there is a danger that this objectification of deficit (its attribution to structural causes) has the effect of 
reducing the agency of black students to that of primary agency (they are no more than the effects of their natal contexts). This position was later reinforced by the obsession in QA and managerial discourse with statistics on academic performance disaggregated by 'race'. The chaotic concept of 'race' as the key marker of identity serves to obscure not only emerging class distinctions, but also the varied effects of cultural structure and the emergent PEPs and identities of students. The objectification of the problem tends to objectify the solutions. The effects of this discursive construction may contribute to impatience with continued black student under-performance. However, subsequent discursive shifts that included the importance of affective factors, the effects of institutional culture, the politics of identity and particularly the adoption of socio-cultural and even ontological theories of learning have served to refine the dominant $A D$ construction of black students.

Secondly, due to early experiences of polarisation and marginalisation, AD discourse tends to stereotype academics as autonomous, uncaring teachers and self-interested researchers. This stereotyping fails to recognise the effects of the situational logic of the institution on academic practice and the fact that any academic who spends extra time on teaching is working against his/her own self-interest.

Academic development practitioners have historically relied on senior leadership to authorise their position and role in the institution. Historically both roles have shared the moral high ground of the equity and human rights discourses. Currently as the situational logic moves to one of correction and compromise, senior managers appear to be increasingly recognising the value of $A D$ practitioners as change managers on the ground. As AD practitioners buy into this new role, their identities and discourses shift from being against the institution to being for it. This is in keeping with the shift in situational logic from elimination to correction and ultimately to protection.

\section{Conclusion}

One needs to ask what the use of Archer's morphogenetic cycle and typologies of situational logics achieved in the meta-analysis? How practical and useful is her theory? Undoubtedly her theory of social change can provide an explanatory methodology for educational research and it could serve to deepen and enrich the methodology for academic review. However, because it operates at such a high level of abstraction, it is sometimes unclear how to operationalise her concepts, leading to the possibility that the theory over-determines the data.

The theory did surface the importance of structural analysis - it illustrated the enduring nature of structural and cultural systems. For example, it showed how an institution with a strong reputation and strong internal system integration could get away with minimal compliance with the state's transformation imperative and in reaction decide to (more aggressively) reproduce its own cultural system and values. It also showed how the enduring nature of structural and cultural systems is likely to continue to constrain the academic performance of working class black students for some time to come-despite huge agential effort by some teachers and some students. However, in carrying out the analysis, methodologically it proved very difficult to maintain Archer's analytic distinction between structural and cultural systems and between SEPs and CEPs. For example the core functions of teaching and research are manifest in practice as both types of system that dialectically reinforce each other.

However, the use of Archer's concepts of SEPs and CEPs did enable an understanding of the structural dynamics of particular situational logics. For example, the analysis was 
able to trace the structural trajectory of the AD project showing that when it was structurally insecure, it operated in a situational logic based on contingent contradictions and remained in a marginal position. However, once structural morphogenesis set in, AD's agency in the institution grew and the contradictions of the situation sharpened to the point where correction and compromise have become necessary.

Archer's conceptualisation of a stratified and developmental understanding of agency is particularly helpful in trying to analyse social change, as it assists in explaining why the agency of some is so much more effective than that of others and the importance of becoming a social actor with a social role. It also allows for both structural positioning and individual difference. Archer's concept of 'double morphogenesis' - that structural transformation inevitably changes the agents (PEPs) involved - is particularly insightful. The process of systems change depends on human agency and in that process people's identities, reasonings and practices are also changed. In fact, what was obscured in an analysis at this level of abstraction is the extraordinary adaptation, ingenuity and moral integrity of individual social actors who choose to act against their own self-interest in situational contexts of severely constraining contradictions. Agential influences and stories related to this project are subjects for a further paper.

Finally, the social realist insights on social change are salutory. The understanding of society as an open system in which a range of stratified structural and cultural systems is operating simultaneously, with different types of agents triggering different casual mechanisms, suggests a situation of great complexity, instability and fragility, in which efforts at social change invariably result in unintended consequences. Agency does not create structure, it can only reproduce or transform it - to a degree - and always incompletely and imperfectly.

\section{Acknowledgements}

Thanks are due to my colleagues Kevin Williams, for help with social realist theory, and lan Scott for help with the history of UCT and the ADP. All errors are mine.

\section{Notes}

1. Teaching expertise was required to support equity students, whilst research was linked to the idea of academic excellence. The resource-intensive nature of both activities served to exacerbate the tensions between them.

2. The state's belated funding of $A D$ may have been a response to concern in the Department of Education about the high failure rates of black students. Nationally, graduation rates for the $2000-2001$ intake are estimated at $50 \%$ for contact universities and at $30 \%$ for all HEIs, while the black completion rate is estimated to be less than half that of the white completion rate. At the same time, discrepancy in participation rates remains $12 \%$ for blacks compared with $60 \%$ for whites - under $5 \%$ of the black potential cohort are succeeding in HE in South Africa (Scott, Yeld, \& Hendry, 2007).

3. From 1990 to 1999 the total enrolment of black students had increased five-fold to almost $30 \%$ of the total enrolment and $40 \%$ by 2008 . Graduation rates for the 2004 cohort were reported as $81 \%$ for whites, $55 \%$ for mainstream South African Africans and $33 \%$ for AD students on Extended Degree Programmes (CHED \& IPD, 2009, p. 6).

\section{References}

Archer, M. (1995). Realist social theory: The morphogenetic approach. Cambridge: Cambridge University Press.

Archer, M. (1996). Culture and agency: The placesof culture in social theory. Cambridge:

Cambridge University Press. 


\section{K. Luckett}

Archer, M. (2000). Being human: The problem of agency. Cambridge: Cambridge University Press.

Badat, S. (2009). Theorising institutional change: Post-1994 South African higher education. Studies in Higher Education, 34(4), 455- 468.

Bhaskar, R. (1979). The possibility of naturalism: A philosophical critique of the contemporary human sciences. Brighton, UK: Harvester.

Centre for Higher Education Development \& Institutional Planning Department (CHED \& IPD). (2009). Teaching and learning at UCT: A report on the 2008 academic year. Cape Town: University of Cape Town.

Clegg, S. (2009). Forms of knowing and academic development practice. Studies in Higher Education, 34(4), 403-416.

Department of Education (1997). Education White Paper 3: A programme for the transformation of higher education. Pretoria: Department of Education.

Higher Education Quality Committee. (2007). Audit report on the University of Cape Town. Unpublished report. Council of Higher Education, Pretoria, South Africa.

Luckett, K. (2010). A 'quality revolution' constrained? A critical reflection on quality assurance methodology from the South African higher education context. Quality in Higher Education, 16(1), 71- 75.

Pawson, R., \& Tilley, N. (1997). Realistic evaluation. London: SAGE.

Rossi, P.H., Lipsey, M.W., \& Freeman, H.E. (2004). Evaluation: A systematic approach. Thousand Oaks, CA: SAGE.

Scott, I., Yeld, N., McMillan, J., \& Hall, M. (2005). Equity and excellence in higher education: The case of the University of Cape Town. In W. Bowen, M. Kurzweil, E. Tobin, \& S. Pichler (Eds.), Equity and excellence in American higher education (pp. 261-284). Charlottesville: University of Virginia Press.

Scott, I., Yeld, N., \& Hendry, J. (2007). Higher education monitor: A case for improving teaching and learning in South African higher education. Pretoria: Council on Higher Education.

University of Cape Town. (2009). Strategic plan discussion document. (Unpublished). University of Cape Town intranet, Cape Town, South Africa. 